\title{
Los medios después de Internet. Una hoja de ruta del periodismo digital
}

CP 2015 , Vol.4-Nº (Monográfico II), pp. 67-68. ISSN 2014-6752. Girona (Catalunya). ÁLVAREZ SABALEGUI, David: Los medios después de Internet. Una hoja de ruta del periodismo digital. Recibido: 18/11/2015 - Aceptado: 20/11/2015

\section{Los medios después de internet.}

José Luis Orihuela

Barcelona

Editorial UOC, 2015.

165 páginas

ISBN 978-84-9064-700-4

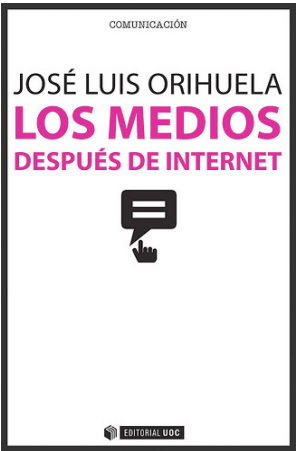

\section{David ÁLVAREZ SABALEGUI}

CEO en Mindset.monica.quintana@mindset.tech

El libro 'Los medios después de internet' lo resume en una breve frase el propio autor, José Luis Orihuela, 'Este es un libro de pistas'. Con esta descripción se da la primera clave de este texto mezcla de estudio académico y reflexiones basadas en la práctica.

La dilatada experiencia del autor en la investigación de los nuevos modos de hacer periodismo da las suficientes garantías para asumir este libro como una hoja de ruta concisa y completa sobre la actual situación de los medios de comunicación en el entorno de internet, así como las tendencias a seguir por parte de los responsables de la profesión del periodismo. El libro es un compendio editado y ordenado de los diferentes textos que José Luis Orihuela publicó en ABC.es y en Infobae.com entre los años 2011 y 2013.

Los textos se ordenan en cinco grandes bloques. El primero corresponde a una descripción y reflexión sobre una de las redes sociales más influyentes en el ámbito del periodismo, Twitter. En este capítulo el autor define el rol de dicha red social en el ecosistema digital de los medios de comunicación, así como el papel que cumple en las entrañas de las redacciones, la relación directa entre red social y periodista.

El segundo bloque lo dedica a las connotaciones de internet como cultura de trabajo en los medios. El enfoque innovador que José Luis Orihuela aporta en su obra está muy basado en la descripción de la transición de lo relevante en este ámbito: del medio al contenido y del contenido a la conversación como generadora de diversas comunidades.

En el tercer bloque se da una descripción breve pero muy reveladora sobre los nuevos modelos de negocio que se están generando alrededor de los medios de comunicación, con ejemplos muy gráficos como los de The Guardian, The Economist y la BBC, alineando dichos modelos con una de las consecuencias directas de este nuevo escenario, la construcción de nuevas 
identidades digitales, tanto corporativas como personales en el caso de los periodistas.

Ese tercer bloque lo enlaza de un modo muy natural con uno de los grandes retos del nuevo periodismo, con el que se crea el cuarto bloque, un capítulo de recomendaciones para la formación de los nuevos comunicadores. Es en este capítulo donde el autor muestra sus dos grandes experiencias, la de la investigación periodística y la de la docencia. Sin duda alguna, este apartado es clave para que los futuros periodistas entiendan el actual contexto del ecosistema periodístico digital.

Para finalizar, el quinto bloque el autor lo dedica a describir diversas tendencias claves del nuevo contexto periodístico. Multiplataformas, periodismo de datos, gestión de las redes sociales, los curadores digitales, la desintermediación de la información y otros conceptos imprescindibles para entender el nuevo panorama de los medios de comunicación después del surgimiento de internet.

Y como no podría ser de otro modo, siendo un libro basado en internet, en él se incluye un extenso catálogo de referencias a textos publicados en el ámbito digital. Links dirigidos a la consulta práctica como apoyo a los cinco grandes bloques del libro. También se incluye una relación bibliográfica muy bien escogida, con los textos y autores más adecuados para entender la filosofía de esta obra.

El libro cumple un objetivo principal, situar al lector en el actual escenario del papel de los medios de comunicación en el entorno digital. Por lo que es un texto dirigido tanto a los profesionales de los medios como a todas las personas que directa $o$ indirectamente tengan que trabajar en el contexto del ecosistema periodístico digital.

\section{Forma de citación}

ÁlVAREZ SABALEGUI, David: Los medios después de Internet. Una hoja de ruta del periodismo digital. Revista Communication Papers, No8 (Monográfico II), páginas 67 a 68. Departamento de Filología y Comunicación de la Universidad de Girona. Recuperado el _ de de 2 de: http://www.communicationpapers.es 